\title{
Improving Retrievals of Cirrus Cloud Particle Size Coupling Lidar and Three-Channel Radiometric Techniques
}

\author{
M. Chiriaco And H. Chepfer \\ Laboratoire de Météorologie Dynamique, IPSL, Palaiseau, France \\ V. NOEL \\ NASA Langley Research Center, Hampton, Virginia \\ A. Delaval and M. Haeffelin \\ Laboratoire de Météorologie Dynamique, IPSL, Palaiseau, France \\ P. Dubuisson \\ Elico, Wimereux, France \\ P. YANG \\ Department of Atmospheric Sciences, Texas A\&M University, College Station, Texas
}

(Manuscript received 18 June 2003, in final form 19 December 2003)

\begin{abstract}
This study is intended to illustrate the potential advantage of combining lidar measurements and the splitwindow technique based on the infrared spectral information contained at the 8.65-, 11.15-, and 12.05- $\mu \mathrm{m}$ bands for inferring the microphysical properties of cirrus clouds. The lidar returns are employed to detect cirrus clouds. The optical properties of nonspherical ice crystals computed from the state-of-the-art scattering computational methods are used for the present forward radiative transfer simulation that fully accounts for both gaseous absorption and multiple scattering processes in the atmosphere. A combination of the radiances at the three infrared (IR) bands with lidar backscatter returns cannot uniquely specify the effective size of ice crystals because of its dependence on the particle aspect ratios. To avoid the shortcoming associated with a potential multivalued retrieval, lidar depolarization observation is used to constrain the specification of the particle aspect ratio in the retrieval implementation based on a precalculated lookup library.

The present methodology for inferring the microphysical properties of cirrus clouds is implemented for nine cases by using the measurements from a 532-nm lidar located at the Palaiseau, France, ground-based site and the infrared spectral bands from the Moderate Resolution Imaging Spectroradiometer (MODIS) on the Terra platform. It is shown that the three IR wavelengths are quite complementary in constraining the retrieval of the particle size, leading to a significant advance in comparison with two-channel techniques, whereas the aspect ratio constraint due to lidar depolarization reduces the uncertainty of retrieved particle size by more than $20 \%$ for $70 \%$ of the cases and more than $65 \%$ for $40 \%$ of the cloud cases.
\end{abstract}

\section{Introduction}

Cirrus clouds play a major role in the radiative energy budget of the earth-atmosphere system (Liou 1986). Their effect is governed primarily by the equilibrium between their albedo effect and their contribution to the greenhouse effect. Both macrophysical and microphysical properties of cirrus clouds regulate this equilibrium.

Corresponding author address: Marjolaine Chiriaco, LMD—Ecole Polytechnique, 91128 Palaiseau Cedex, France.

E-mail: chiriaco@1md.polytechnique.fr
To quantify the effect of cirrus clouds in climate and weather systems, the global coverage, altitude, temperature, vertical structure, and spatial inhomogeneities of these clouds must be properly accounted for. Additionally, the ice water content and its spatial distribution are critical to the global radiative effect of cirrus clouds. One of the main uncertainties on the radiative impact of cirrus clouds is due to the poor knowledge of the natural variability of their microphysical properties, such as the size, shape, and orientation of ice crystals in space. The effective size of ice crystals composing cirrus clouds is a quite important microphysical param- 
eter, as it largely affects cloud albedo. For example, the reflectance of a cloud increases with the decrease of particle effective size if the ice water content of the cloud is conserved.

For global remote sensing and long-term monitoring of the effective sizes of ice crystals, satellite instruments are the best sources for observations. On a local scale, various midlatitude intensive field experiments, such as the First International Satellite Cloud Climatology Project (ISCCP) Regional Experiment (FIRE), the European Cloud and Radiation Experiment (EUCREX), and the International Cirrus Experiment (ICE) (Randall et al. 1996; Raschke et al. 1998; McFarquhar and Heymsfield 1996; Toon and Miake-Lye 1998), as well as a few tropical campaigns such as the Central Equatorial Pacific Experiment (CEPEX) and the recent Cirrus Regional Study of Tropical Anvils and Cirrus LayersFlorida Area Cirrus Experiment (CRYSTAL-FACE) have collected a wealthy amount of in situ data that show a strong variability of the particle size of cirrus clouds, either from one cloud to another or within a single cloud (Heymsfield 1975, 1993; Heymsfield and Platt 1984; Krupp 1991; Miloshevich and Heymsfield 1996). Improved knowledge of realistic sizes and shapes of ice crystals on the basis of in situ measurement has led to an improvement in the computation of the scattering properties of ice crystals (Wendling et al. 1979; Takano and Liou 1989; Macke et al. 1996; Yang and Liou 1998). In parallel, various remote sensing retrieval techniques have been developed to infer the ice crystal sizes from ground-based observations using active sensors (Platt et al. 1989; Intrieri et al. 1993, 1995; Mace et al. 1998; Matrosov 1999) and from satellite observations using passive sensors. One of the widely used retrieval algorithms in the literature is the so-called splitwindow technique (Inoue 1985; Parol et al. 1991; Giraud et al. 1997), which is based essentially on the different absorption features of ice at two channels located within the atmospheric IR window. It is worth noting that other methods such as those reported by Minnis et al. (1998), King et al. (2003), and Platnick et al (2003) are also quite powerful for inferring the microphysical properties of ice clouds.

The upcoming Cloud-Aerosol Lidar and Infrared Pathfinder Satellite Observations (CALIPSO) mission, scheduled to be launched in 2005, will feature a threechannel $(8.7,10.5,12 \mu \mathrm{m})$ infrared imager (IIR) and a backscatter lidar operating at the 532-nm wavelength with depolarization capability. Those instruments will be on the same platform and will collect collocated measurements. The intent of the present paper is to highlight the potential advantage of coupling the passive and active sensing measurements for increasing the confidence in the particle size retrieval. Especially, it is shown that lidar observations can be quite useful to constrain the well-known weaknesses of the split-window technique, such as the cloud identification, the altitude and real temperature of the cloud layer, and the information on true cloud phase and aspect ratio of cloud particles.

\section{Tools and method}

a. Observations

Several cloud cases observed at the Site Instrumental de Recherche par Télédétection Atmosphérique (SITRA), Palaiseau, France, ground-based site are investigated in this study. Measurements from an active ground-based sensing facility and a spaceborne passive instrument are used, which are briefly described as follows:

1) A satellite-borne spectroradiometer. The Moderate Resolution Imaging Spectroradiometer (MODIS) on Terra flies over Palaiseau 1 or 2 times per day, depending on the Terra orbit. The full MODIS resolution is $1 \mathrm{~km}$, and for the current study, data are navigated by blocks of $5 \times 5$ pixels $\left(5 \times 5 \mathrm{~km}^{2}\right)$. Only the brightness temperatures $\left(T_{B}\right)$ observed in the MODIS channels close to the IIR/CALIPSO channels are considered. The relevant MODIS and IIR/CALIPSO filters are shown in Fig. 1.

2) A ground-based 532- $\mathrm{nm}$ lidar. The SIRTA 532-nm lidar is similar to the one that will be onboard the CALIPSO platform. It operates 4 days a week from 8 A.M. to 8 P.M., with a temporal resolution of 20 shoots per second and a vertical resolution of $15 \mathrm{~m}$. It is a zenith-viewing lidar that measures both the backscattered signal and linear depolarization ratio. The lidar observations are treated as follows: (i) the two 532-nm signals (parallel and perpendicular polarization) are normalized to the molecular signal, (ii) the cloud-base and -top altitudes are derived from the lidar profiles averaged over $1 \mathrm{~min}$ in the parallel channel using a threshold method, and (iii) the linear depolarization ratio is the ratio of the perpendicular to the parallel channel. The cloud-top and -base real temperatures and the ground-based temperature are derived from the coupling of the cloud altitude (derived from the lidar) with the temperature profile obtained by radiosondes launched twice per day (0000 and 1200 UTC) from the Trappes station (MétéoFrance), located $15 \mathrm{~km}$ away from the SIRTA ground-based site.

A total of nine different cases of observations have been analyzed for the current study. The clouds chosen are relatively constant in time and in space in order to have a good collocation between the lidar and the satellite measurements. Table 1 summarizes the dates and time periods of observations for the different instruments, and the altitudes of each cloud.

\section{b. Theoretical tools}

1) CRystal optical PROPERTIES IN THE INFRARED

Various ice crystal shapes and sizes have been observed in cirrus clouds (e.g., Magono and Lee 1966; 


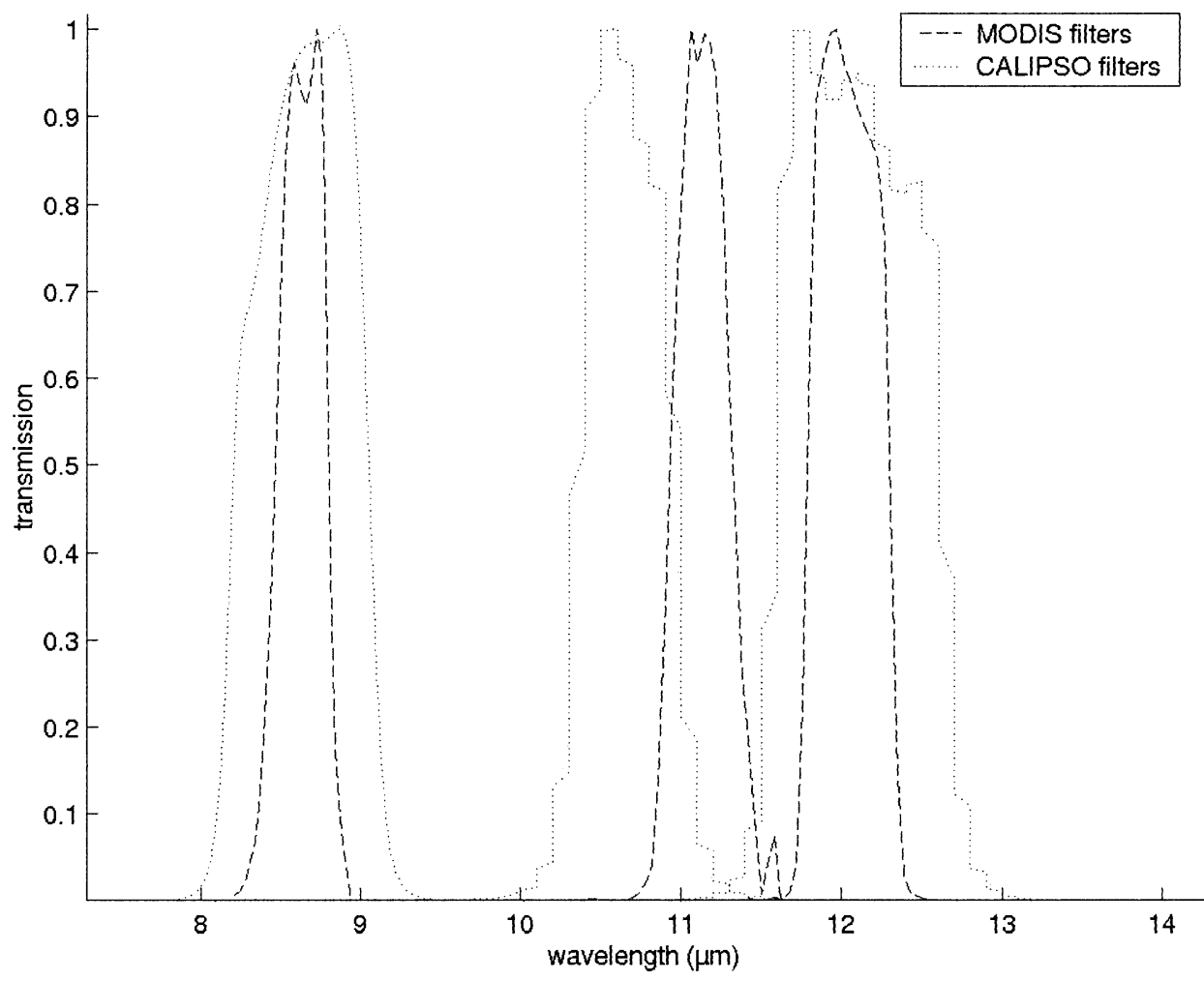

FIG. 1. Spectral response of IIR/CALIPSO filters and MODIS filters for 8.65-, 11.15-, and 12.05- $\mu \mathrm{m}$ channels.

Miloshevich and Heymsfield 1996). One is unlikely to include the morphological details of ice crystals in computing their microphysical properties for remote sensing application. A common practice is to make an a priori choice of particle shape for retrieval applications. For the present study, this choice is mainly directed by the availability of optical properties consistently computed at $8.65,11.15,12.05 \mu \mathrm{m}$, and $532 \mathrm{~nm}$, including the scattering matrix for interpretation of the lidar depolarization. For this reason, we consider simple hexagonalbased crystal geometry with various aspect ratios $Q$ (ratio of the particle length to the particle diameter) ranging between 0.15 and 2.5 . The effective size $r_{e}$ retrieved in this study corresponds to the size of a sphere with equivalent volume to the hexagonal crystal considered.

For those nonspherical particles, in the infrared wavelength domain, the optical properties are computed with various methods depending on the size of the crystal compared to the wavelength of interest: a mix of improved ray-tracing computation for large sizes and finite difference-time domain calculations for small sizes (Yang et al. 2001). In the visible, the scattering matrix is computed with a classical ray-tracing method (Takano and Liou 1989; Noel et al. 2001).

For spherical particles, in both infrared and visible wavelengths, the optical properties are computed with the Mie theory for standard Deirmendjian (1969) size distributions $\mathrm{C} 1\left(r_{e}=6 \mu \mathrm{m}\right)$ and $\mathrm{Cu}\left(r_{e}=12 \mu \mathrm{m}\right)$. The refractive indices for water and ice come from Warren (1984).

Table 2 summarizes the different aspect ratios and sizes taken into account for the current study. For illustration, the optical properties are given at $8.65 \mu \mathrm{m}$. The asymmetry factor varies between 0.03 and 0.99 , and the single scattering albedo between 0.05 and 0.79 .

\section{2) RADIATIVE TRANSFER COMPUTATION IN THE INFRARED}

To compute the radiances in the infrared domain at the top of the atmosphere, we need to know the composition of the atmosphere, the surface emissivity, and the composition of clouds. In this study we use the radiative transfer code developed by Dubuisson et al. (1996), which accounts for absorption by atmospheric gases on the basis of the line-by-line method (Scott 1974), and the emission and scattering processes within cirrus clouds on the basis of the discrete ordinate method (Stamnes et al. 1988). Fifty atmospheric levels are used in the radiative transfer computation, in which temperature and pressure are specified according to in situ data (radiosonde) of temperature and pressure profiles. Various aspect ratios and sizes of ice crystals are considered for cirrus clouds [section $2 b(1)$ ]. Surface emissivities are deduced from MODIS observations (Y. Hu 2002, 


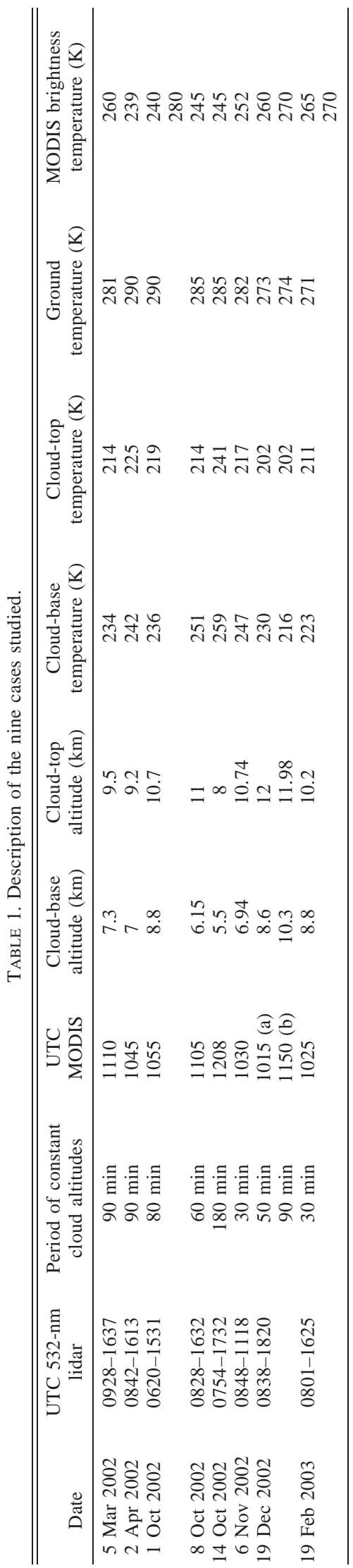

personal communication): typically, $\varepsilon_{8.65 \mu \mathrm{m}}=0.93$, $\varepsilon_{11.15 \mu \mathrm{m}}=0.95$, and $\varepsilon_{12.05 \mu \mathrm{m}}=0.96$. Those values have been used in the radiative transfer code to compute brightness temperatures at the top of a clear atmosphere integrated on the MODIS filters. Those computed values have been compared with values measured by MODIS/ Terra during a clear-sky situation identified with the lidar data in order to see their consistency.

\section{c. Method}

The present method is intended to retrieve the size of the ice crystals in semitransparent cirrus clouds. In this study we consider only thin cirrus clouds for which the backscatter 532-nm lidar signal from the bottom to the top of the cloud can be observed. Typically, these clouds have optical depths less than 3 . The method is based on three infrared channels: the brightness temperature differences between two of those channels measured from space are compared to their counterparts computed for various ice crystal models (size and aspect ratio). The channels considered are centered at 8.65, 11.15 , and $12.05 \mu \mathrm{m}$ as selected for the future IIR/ CALIPSO mission (Fig. 1). The brightness temperatures are computed by using the radiative transfer code described in section $2 b(2)$. The cloud-base and -top altitudes are determined with the 532-nm lidar. Those altitudes are associated with a collocated radiosonde (15 $\mathrm{km}$ from the SIRTA, launched every day at 1200 UTC) to get the cloud-top and -base temperatures. Then, for each cloud case studied, the surface and clear-sky atmosphere properties, as well as the cloud real temperature, are prescribed in the radiative transfer code following Table 3. For a cloudy atmosphere, various microphysical properties, including spherical and nonspherical particles, are used in the radiative transfer computations. The comparison between the brightness temperature differences computed and measured allows the selection of several microphysical models (size and aspect ratio), which matches the observations. Another constraint on the particle aspect ratio (from lidar depolarization) allows reduction of the number of solutions, leading to an optimized selection of a microphysical model (size and aspect ratio).

\section{Application of the method}

a. Cloud-type identification and semitransparent clouds

\section{1) $\mathrm{APPROACH}$}

Figure 2 shows an example of the classical approach (Inoue 1985) for implementing the split-window technique: the brightness temperature differences between two channels ( $y$ axis) are plotted as a function of the brightness temperature in one of those channels ( $x$ axis). Each curve corresponds to a particle model as given in Table 2. The warm foot of the arches corresponds to a 


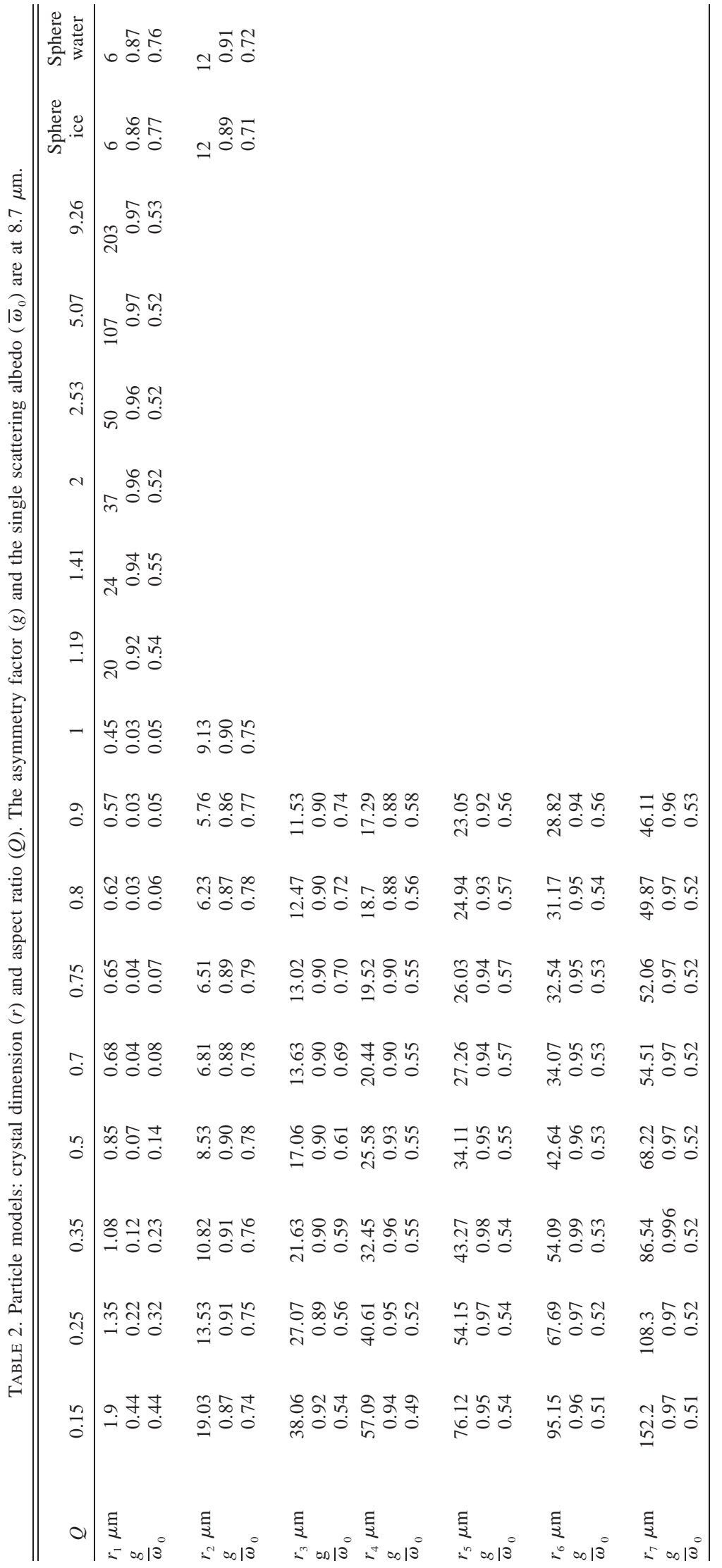


TABLE 3. Cloud and clear-sky properties used for retrieval of the particle size. FDTD is finite-differential time domain, and IGOM is Improved Geometrical Optic Model.

\begin{tabular}{|c|c|}
\hline Properties & Deduced from \\
\hline \multicolumn{2}{|c|}{ Clear sky and surface } \\
\hline Surface real temperature & Ground-base thermometer (SIRTA) \\
\hline Surface emissivities & MODIS map* around SIRTA site \\
\hline Humidity and gazes profiles for clear-sky conditions & $\begin{array}{l}\text { Radiosonde when clear-sky conditions available or McClatchey et } \\
\text { al. (1972) when radiosonde does not document clear sky }\end{array}$ \\
\hline \multicolumn{2}{|c|}{ Cloudy atmosphere } \\
\hline Presence of cloud & Ground-based backscattered lidar (SIRTA) \\
\hline Cloud real temperature & $\begin{array}{l}\text { Ground-based backscatter lidar (SIRTA) + temperature profile (ra- } \\
\text { diosonde; Météo France) }\end{array}$ \\
\hline Brightness temperature & MODIS/Terra \\
\hline \multicolumn{2}{|l|}{ Top of the atmosphere } \\
\hline Ice crystal optical properties & $\begin{array}{l}\text { FDTD and IGOM for nonspherical particles (Yang 1998) Mie theo- } \\
\text { ry for spherical particles, C1, Cu (Deirmendjian 1969) }\end{array}$ \\
\hline Ice crystal shape constraint & Ground-based depolarization lidar (Noel et al. 2002; SIRTA) \\
\hline
\end{tabular}

* Y. Hu 2002, personal communication.

clear-sky situation. When the brightness temperature decreases, the optical depth increases, and the different curves separate from each other. Whatever the hypothesis microphysical properties, the curves converge to the cold foot of the arches, which corresponds to an opaque cloud situation.

Figure 2 clearly shows that the position of the cold foot is a key factor for the representation of the brightness temperature difference and hence for the particle size retrieval. The cold foot brightness temperature $T_{B}^{\mathrm{bb}}$ is the brightness temperature that would be measured by the spaceborne radiometer if the cloud under study were a blackbody. In most of the previous studies (e.g., Inoue 1985; Parol et al. 1991; Giraud et al. 1997), the cold foot was determined using the pixels in the vicinity of the cloudy pixels under study, which was assumed to correspond to the coldest brightness temperature observed in the region. This assumption reduces the applicability of the method to scenes where opaque ice clouds are close to semitransparent clouds. Moreover, a spatial homogeneity of the cloud altitude and optical properties of the entire cloud parcel has to be assumed.

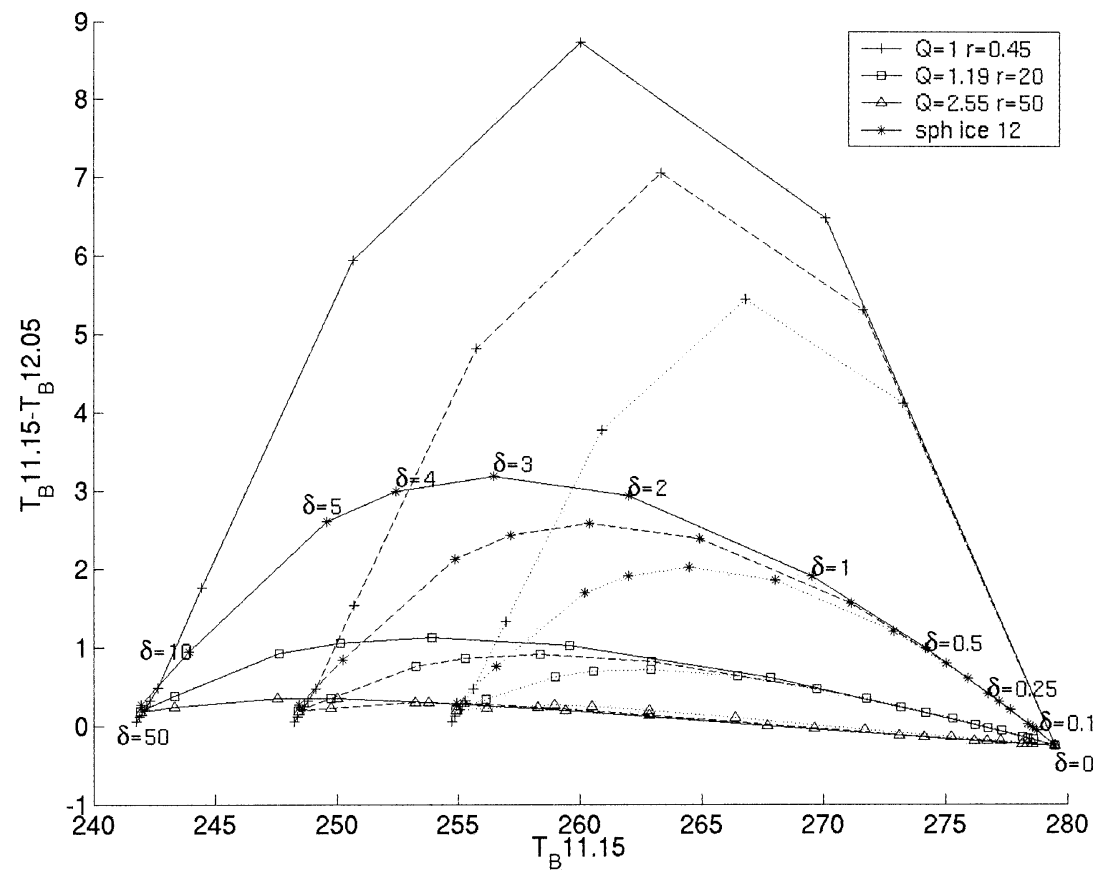

FIG. 2. Example of the split-window technique for different positions of the cold foot: cold foot at the cloud-top temperature in full line, at the cloud middle temperature in dashed line, and at the cloud-base temperature in dotted line. Each curve corresponds to a particle model; each point corresponds to an optical depth $\delta$. 

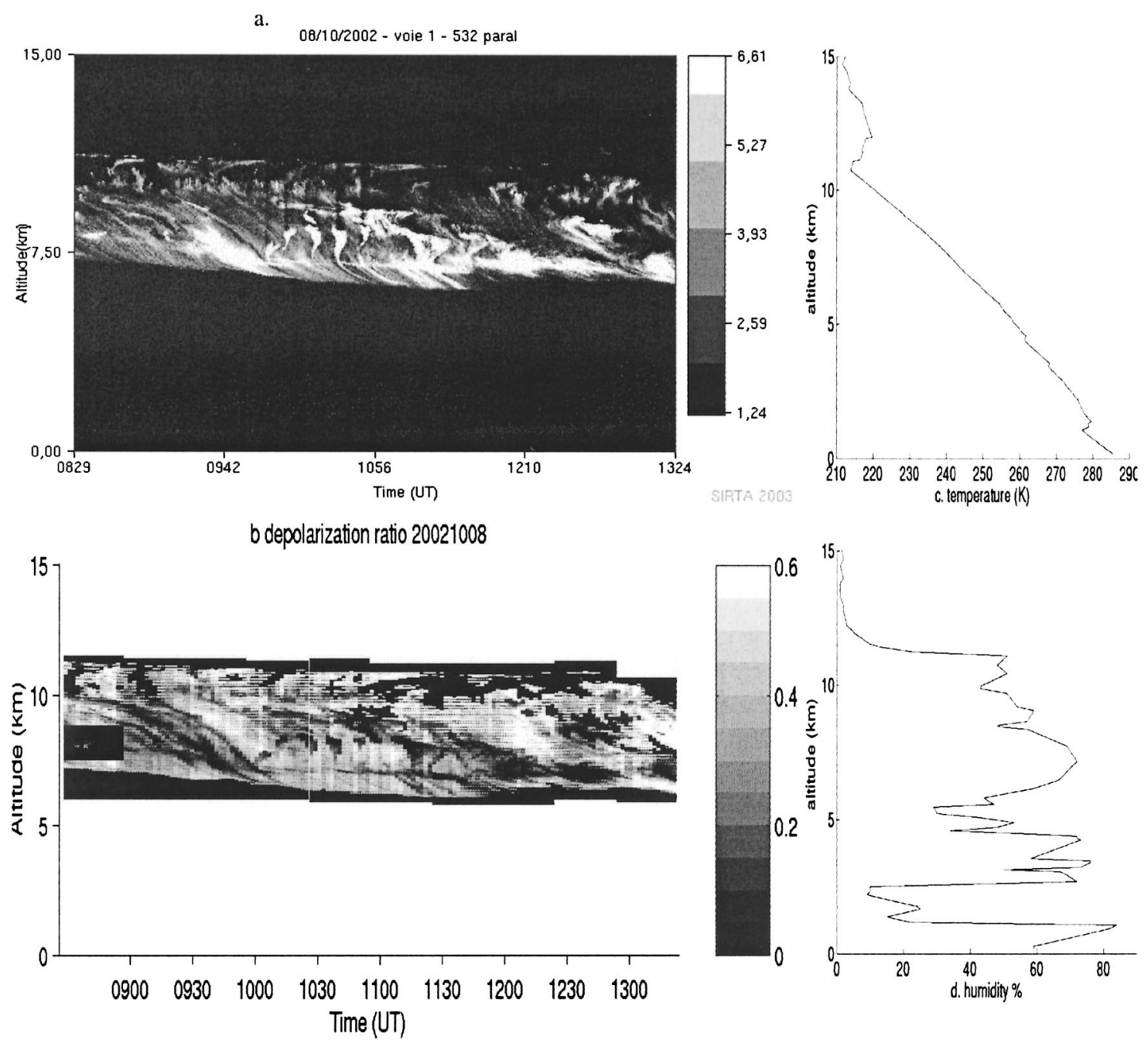

FIG. 3. For 8 Oct 2002: (a) evolution of the 532-nm lidar backscattered signal as a function of time, (b) same as in (a) but for 532-nm lidar depolarized signal; (c) temperature and (d) humidity profile from radiosonde.

Because of those limitations, the split-window technique is currently applicable to few cloud cases, where all the points of the complete arches can be described by using the brightness temperatures observed within a small cloud area. In the current study, this value is computed with a radiative transfer code for an atmosphere containing an opaque cloud (typically with an optical depth of 50) located at the same altitude (i.e., temperature $T^{\text {cloud})}$ as the cloud under study. Lidar and radiosonde data are used to estimate the true cloud temperature ( $\left.T^{\text {cloud }}\right)$, which is usually unknown. Therefore, the splitwindow technique can be extended to a significant amount of cloud coverage over the globe.

This approach can potentially be applicable to all types of cirrus clouds; nevertheless there are still some uncertainties depending on the cloud level for specifying the blackbody temperature. Actually, the base, middle, and top cloud temperatures could differ by several de- grees. The impact of this uncertainty will be discussed in section 5 .

\section{2) Example of CASe Study: 8 OCTOBer 2002}

Figure 3 a shows the evolution with time and altitude of the 532-nm lidar backscattered signal. This image indicates a cloud located between 6 and $11 \mathrm{~km}$, with a constant altitude, making it a good case study. Figure $3 \mathrm{~b}$ shows the evolution with time and altitude of the 532-nm lidar depolarization ratio ranges between $20 \%$ and $60 \%$ within the cloud. Figure $3 \mathrm{c}$ represents a temperature profile from a radiosonde. The cloud temperature $\left(T^{\text {cloud }}\right)$ ranges from 220 to $250 \mathrm{~K}$. Furthermore, for this day, the ground temperature ( $\left.T^{\text {ground }}\right)$ was 286 K. On 8 October 2002, MODIS/Terra flew over the SIRTA at 1105 UTC. As it is shown by the lidar image (Fig. 3a), the cloud altitudes are constant during $1 \mathrm{~h}$ 


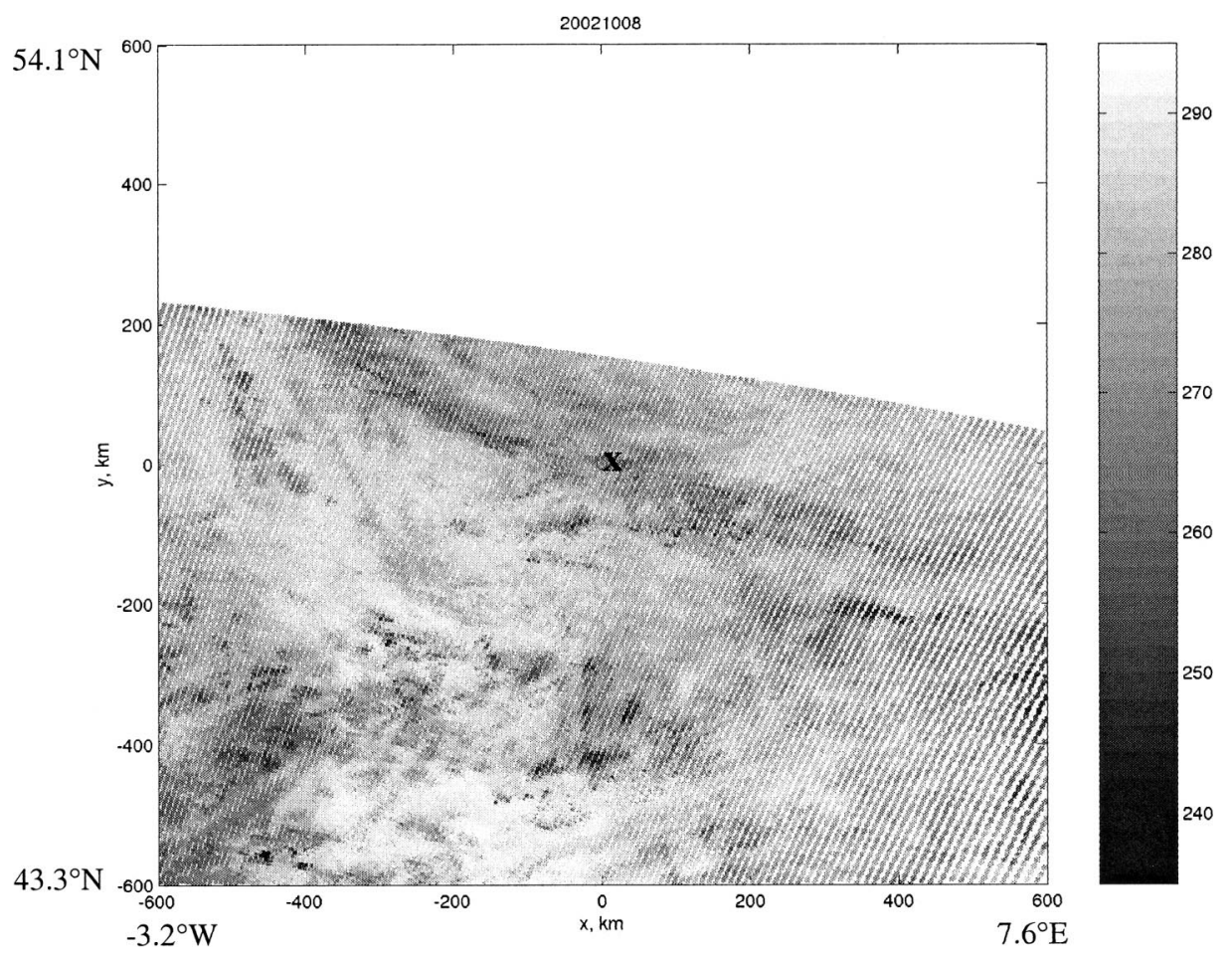

FIG. 4. MODIS image in brightness temperature at $8.65 \mu \mathrm{m}$; " $\mathrm{X}$ " is the location of the SIRTA $\left(48.713^{\circ} \mathrm{N}, 2.204^{\circ} \mathrm{E}\right)$.

around the time of the satellite overpass. The MODIS/ Terra brightness temperature in the $8.65-\mu \mathrm{m}$ channel $T_{B}^{\text {cloud }}(8.65 \mu \mathrm{m})$ over SIRTA is $265 \mathrm{~K} \pm 2.8(1 \sigma)$, and this temperature is relatively constant for the $60 \times 60$ $\mathrm{km}^{2}$ around the SIRTA (Fig. 4), which confirms that the same cloud is measured by both instruments. The measured cloud brightness temperature at $8.65 \mu \mathrm{m}(265 \mathrm{~K})$ is larger than the one that would be measured for an opaque cloud $(217 \mathrm{~K})$ located at the true cloud temperature $(220$ to $250 \mathrm{~K})$. It shows that the surface influences the satellite observation because the cloud is semitransparent. The theoretical brightness temperatures are computed for a $286-\mathrm{K}$ surface and a cloud with a real temperature of $220 \mathrm{~K}$ (the real temperature at the top of the cloud), with various optical depths ranging between 0 and 50, and for several particle models (one aspect ratio associated to one size). The calculations are computed for the two MODIS wavelengths: 11.15 and $12.05 \mu \mathrm{m}$. Figure 5a shows the brightness temperature differences between the 11.15- and 12.05- $\mu \mathrm{m}$ MODIS channels as a function of the brightness temperature in the $11.15-\mu \mathrm{m}$ channel. The 25 MODIS pixels over the SIRTA are plotted as dots on the figure. The dots cover only a part of the arch, but as the arch is correctly positioned (i.e., the cold and hot foot are fixed with the lidar and radiosonde), the dots can be interpreted as a signature of the cloud microphysics. Actually, the cold foot brightness temperature is about $218 \mathrm{~K}$ (a few less than the real cloud temperature because of the presence of the other components of the atmosphere), whereas the MODIS brightness temperatures range between 255 and $270 \mathrm{~K}$. Hence, the cloud is not opaque but semitransparent. Comparing the calculations and the data leads to particle sizes between 17 and $26 \mu \mathrm{m}$ for aspect ratios ranging between 0.15 and 0.9 . Nevertheless, the size range is relatively large; therefore, this result will be improved by other constraints.

\section{b. Combination of three wavelengths}

\section{1) APPROACH}

Figure 6 shows an example of a result of computation at the three wavelength pairs $(8.65,11.15,12.05 \mu \mathrm{m})$ for one particle aspect ratio $(Q=0.5)$ and various sizes. It illustrates that the 11.15- and 12.05- $\mu \mathrm{m}$ channels (Fig. 6c) do not allow distinguishing sizes higher than $57 \mu \mathrm{m}$. Figure $6 \mathrm{~b}$ shows that the brightness temperature differences are higher when considering the 8.65- $\mu \mathrm{m}$ channel; hence, the size can be determined up to $76 \mu \mathrm{m}$. These higher brightness temperature differences are due to the scattering phenomena being more important at $8.65 \mu \mathrm{m}$ compared to 11.15 and $12.05 \mu \mathrm{m}$. Hence, in order to constrain the size result found in section $3 \mathrm{a}(2)$, the split window is applied to three wavelengths instead of two.

\section{2) EXAMPle OF CASE STUdy: 8 OCTOBER 2002}

Figure 5 shows the split-window technique for the three wavelength pairs applied to the same cloud in 

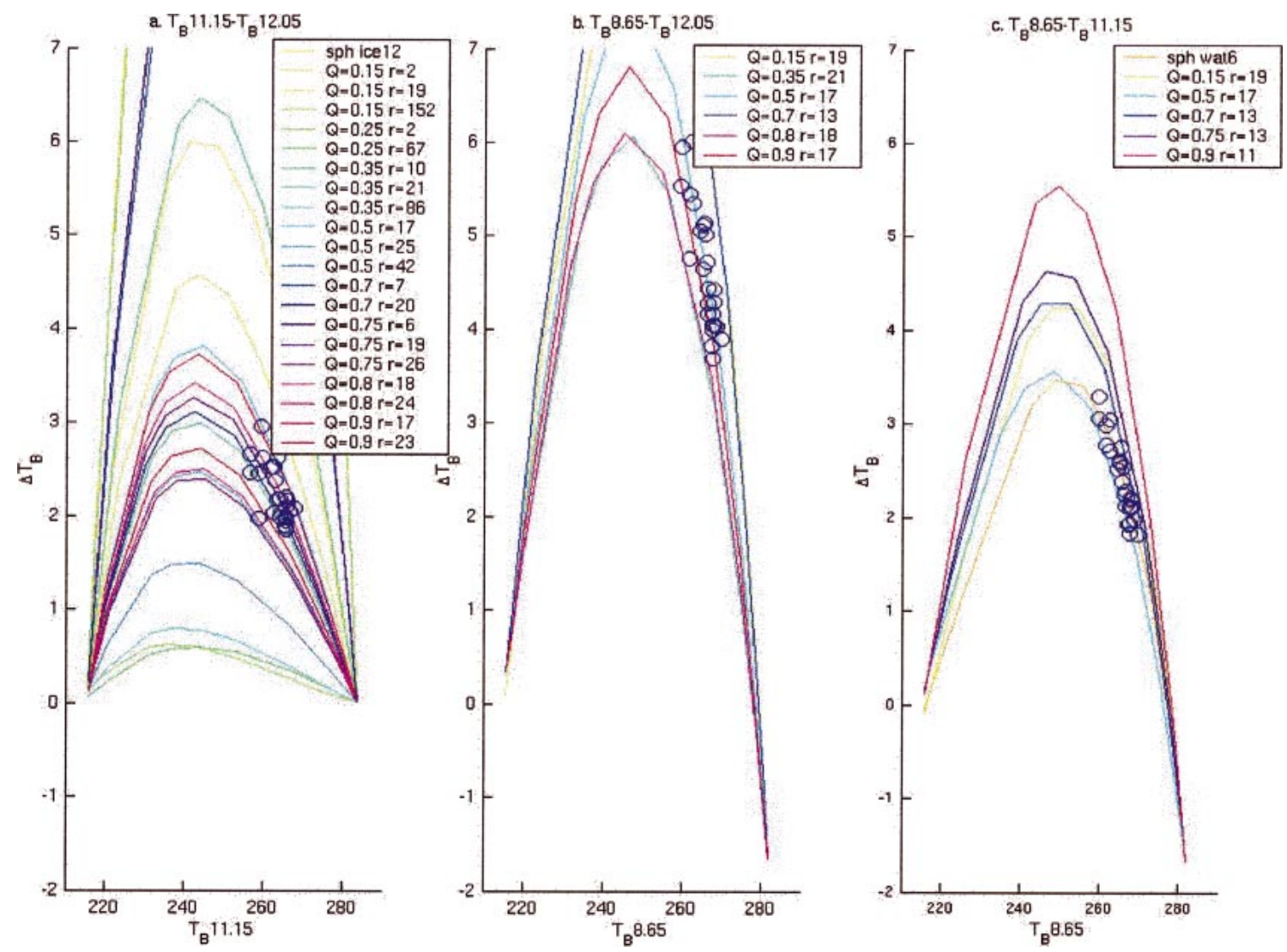

FIG. 5. Brightness temperature differences between two infrared channels as a function of the brightness temperature in one channel: (a) $T_{B, 11.15 \mu \mathrm{m}}-T_{B, 12.05 \mu \mathrm{m}}=f\left(T_{B, 11.15 \mu \mathrm{m}}\right)$; (b) $T_{B, 8.65 \mu \mathrm{m}}-T_{B, 12.05 \mu \mathrm{m}}=f\left(T_{B, 8.65 \mu \mathrm{m}}\right)$; and (c) $T_{B, 8.65 \mu \mathrm{m}}-T_{B, 11.15 \mu \mathrm{m}}=f\left(T_{B, 8.65 \mu \mathrm{m}}\right)$. Experimental data are in dots.

section 3a. The 25 MODIS pixels over the SIRTA are plotted as dots in each figure. For the three wavelength pairs, the dots cover only a part of the arch, but as the arch is correctly positioned (i.e., the cold and hot foot are fixed with the lidar and radiosonde), the dots can be interpreted as a signature of the cloud microphysics. For each wavelength pair, the calculations are compared to the data:

1) Channels 11.15 and $12.05 \mu \mathrm{m}$ (Fig. 5a) lead to particle sizes between 17 and $26 \mu \mathrm{m}$ for aspect ratios ranging between 0.15 and 0.9 .

2) Channels 8.65 and $12.05 \mu \mathrm{m}$ (Fig. 5b) show that the size ranges between 13 and $21 \mu \mathrm{m}$ for aspect ratios ranging between 0.15 and 0.9 .

3) Channels 8.65 and $11.15 \mu \mathrm{m}$ (Fig. 5c) give sizes ranging between 6 and $19 \mu \mathrm{m}$ for spherical shapes and aspect ratios between 0.15 and 0.9 .

Keeping only the particle models that are able to satisfy the three couples of infrared wavelengths (Figs. 5a-c), only two particle models are relevant: a particle size $r$ $=17 \mu \mathrm{m}$ associated with the aspect ratio $Q=0.15$ and a particle size $r=19 \mu \mathrm{m}$ associated with the aspect ratio $Q=0.5$. Hence, for this case, the particle effective radius is ranging between 17 and $19 \mu \mathrm{m}$, and the aspect ratio is ranging between 0.15 and 0.5 . The size interval has been reduced by $7 \mu \mathrm{m}$ by the three-wavelength constraint compared to the size retrieved in section $3 a(2)$.

\section{c. Impact of the particle aspect ratio hypothesis on the retrieved size}

\section{1) $\mathrm{APPROACH}$}

This section is devoted to studying the impact of the particle shape hypothesis on the retrieved size. Figure 7 shows the brightness temperature difference simulated for a given particle size $(r \approx 20 \mu \mathrm{m})$ and various aspect ratios. It clearly illustrates that the brightness temperature differences are very sensitive to the aspect ratio. Particularly, the $8.65-\mu \mathrm{m}-12.05-\mu \mathrm{m}$ pair has a brightness temperature difference ranging between 5 and $8 \mathrm{~K}$ for an aspect ratio between 0.15 and 0.9 . For this reason, it is important to consider various aspect ratios. Several remote sensing techniques (e.g., Sassen and Liou 1979; Sassen and Petrilla 1986; Sassen 1991; Baran et al. 2001; Chepfer et al. 1998, 2001; Masuda et al. 2002; Noel et al. 2002) using passive or active sensors have been developed to infer information on the particle as- 

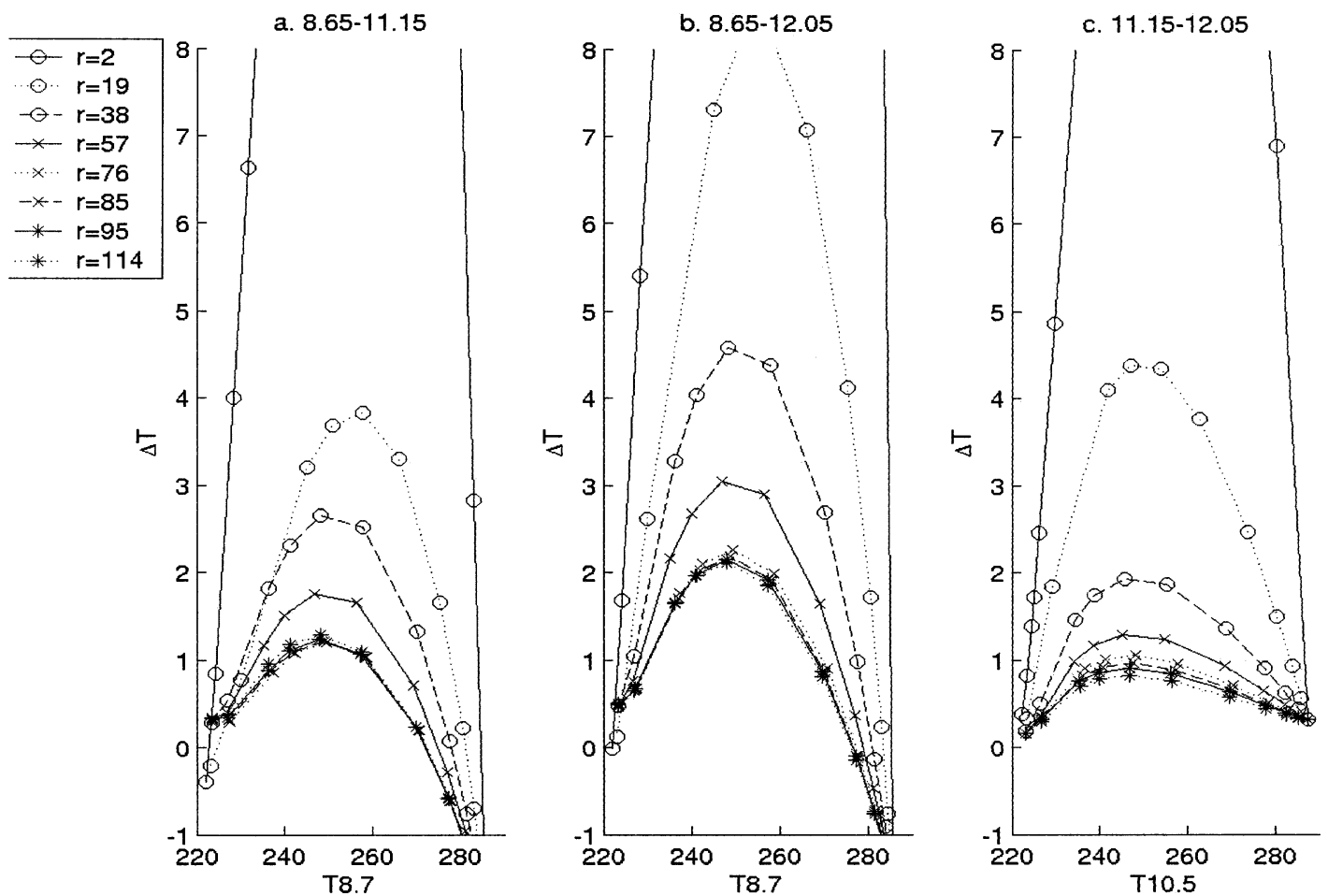

FIG. 6. Split-window sensitivity to large particles for a fixed aspect ratio $Q=0.5$ : (a) $T_{B 8.65 \mu \mathrm{m}}-T_{B 11.15 \mu \mathrm{mm}}=f\left(T_{B 8.65 \mu \mathrm{m}}\right)$; (b) $T_{B .8 .65 \mu \mathrm{m}}-T_{B .12 .05 \mu \mathrm{m}}=f\left(T_{B .8 .65}\right)$; and (c) $T_{B, 11.15 \mu \mathrm{m}}-T_{B, 12.05 \mu \mathrm{m}}=f\left(T_{B, 11.15 \mu \mathrm{m}}\right)$. On one curve, each point corresponds to an optical depth: from right to left, $\delta=0,0.1,0.25,0.5,1,2,3,4,5,10,50$.
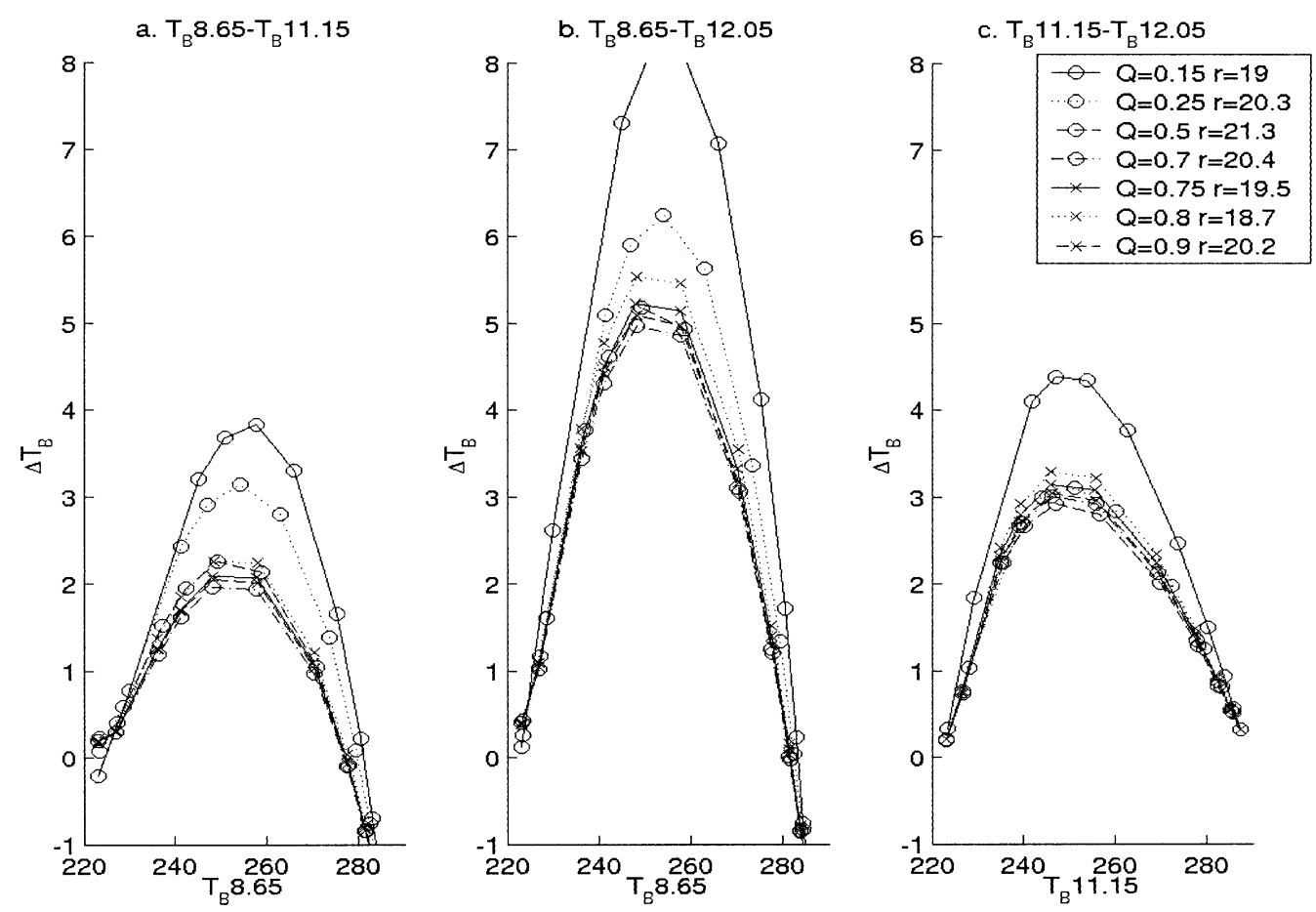

FIG. 7. Split-window sensitivity to the shape for a fixed size $r \approx 20 \mu \mathrm{m}$ : (a) $T_{B 8.65 \mu \mathrm{m}}-T_{B .11 .15 \mu \mathrm{m}}=f\left(T_{B 8.65 \mu \mathrm{mm}}\right.$ ); (b) $T_{B .865 \mu \mathrm{m}}-T_{B, 1205 \mu \mathrm{m}}=f\left(T_{B .865 \mu \mathrm{m}}\right)$; and (c) $T_{B, 11.15 \mu \mathrm{mm}}-T_{B, 12.05 \mu \mathrm{m}}=f\left(T_{B .11 .15 \mu \mathrm{m}}\right)$. On one curve, each point corresponds to an optical depth: from right to left, $\delta=0,0.1,0.25,0.5,1,2,3,4,5,10,50$. 


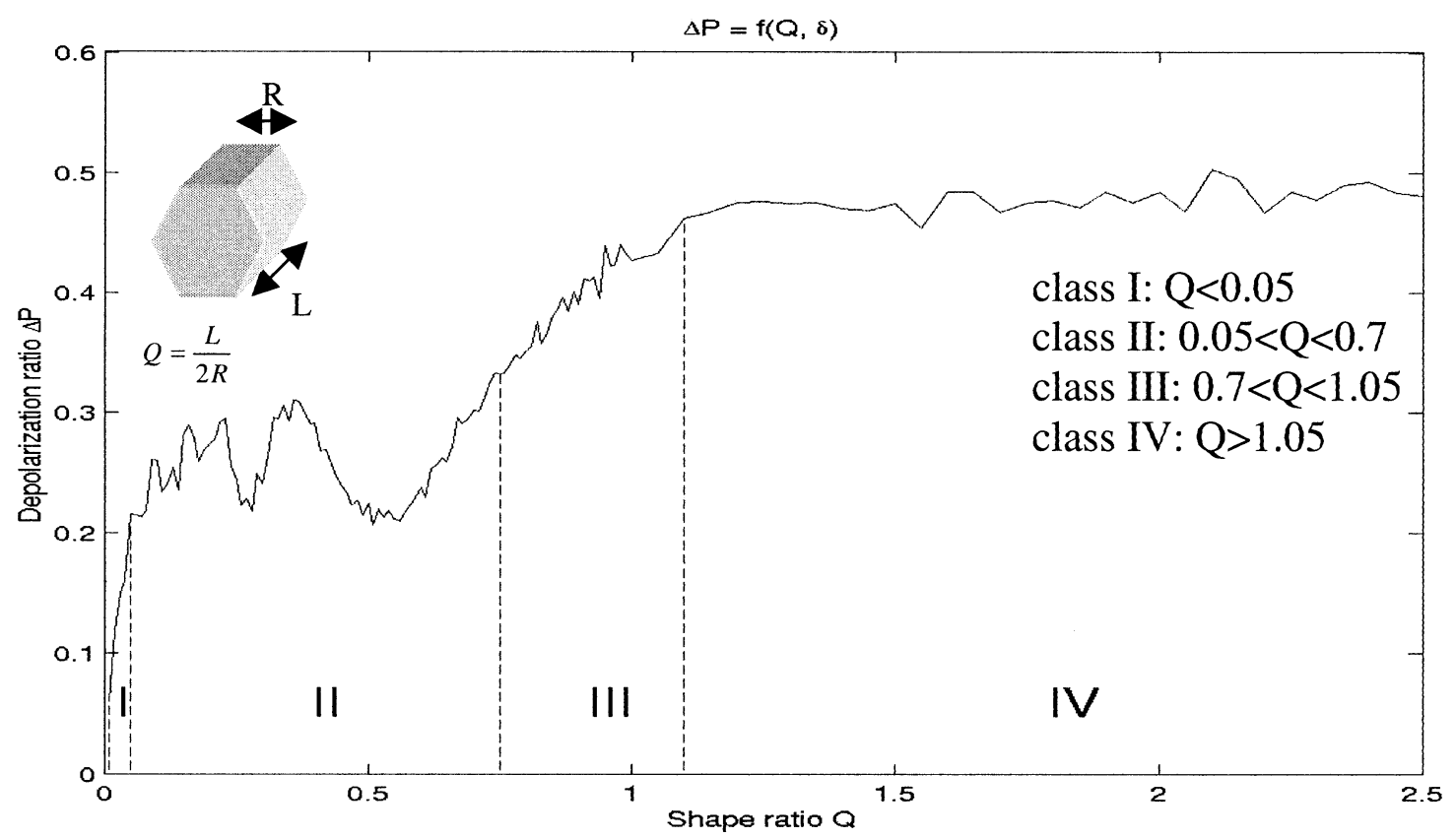

FIG. 8. Simulation of the 532-nm lidar depolarization ratio $\Delta P$, as a function of the aspect ratio $Q$.

pect ratio or particle shape. Because lidar observations will be collected simultaneously to the infrared radiances onboard the CALIPSO platform, we used the lidar depolarization ratio to 1) discriminate the real phase (ice or liquid) of the water within the cirrus cloud, and 2) provide a best guess for the ice crystal aspect ratio when it is not spherical.

In the case of ice crystals randomly oriented in space, which contain a plane of symmetry when using the single scattering approximation, the linear depolarization ratio measured with the lidar can be written as

$$
\Delta P=\frac{P 22(\pi)-P 11(\pi)}{P 22(\pi)+P 11(\pi)},
$$

where $P 22(\pi)$ and $P 11(\pi)$ are the first two diagonal elements of the scattering matrix of the crystal in the backscattering direction (van de Hulst 1957). For spherical particles, those elements are deduced from the Mie theory and from ray-tracing computations for nonspherical particles in the visible domain.

1) The discrimination of the real phase is simply based on the hypothesis that liquid clouds are composed of spherical particles and the ice particles are nonspherical. Following Eq.(1), the linear depolarization $\Delta P=0$ for spherical particles, and $\Delta P=0$ for nonspherical ice crystals, if multiple scattering phenomena are neglected.

2) The determination of a best guess for the particle aspect ratio is based on the dependence of the value of $\Delta P$ to the aspect ratio of the crystal $(Q)$ as shown in Noel et al. (2002). Figure 8 illustrates the relationship between the linear depolarization ratio $(\Delta P)$ and the aspect ratio of the ice crystal $(Q)$. It shows that one value of the linear depolarization ratio can allow the determination of the most probable aspect ratio. However, the relationship between $\Delta P$ and $Q$ is not unique, and one value of $\Delta P$ can be interpreted with different values of the aspect ratio, in particular when the aspect ratio is ranging between 0.3 and 0.4. However, at least four classes of particle aspect ratios can be defined with this method: $0<Q<0.05$ (class I), $0.05<Q<0.7$ (class II), $0.7<Q<1.1$ (class III), and $1.1<Q<\infty$ (class IV).

\section{2) ExAmple of CASE Study: 5 MARCh 2002}

Figure 9a shows the evolution with time and altitude of the 532-nm lidar backscattered signal. It indicates a cloud layer located between 7.5 and $9.5 \mathrm{~km}$. The lidar depolarization ratio (Fig. 9b) ranges between $40 \%$ and $60 \%$. The temperature profile (Fig. 9c), coupled with the cloud altitude, leads to a cloud real temperature ( $\left.T^{\text {cloud }}\right)$ between 215 and $230 \mathrm{~K}$, with a ground temperature ( $\left.T^{\text {ground }}\right)$ of $281 \mathrm{~K}$.

On 5 March 2002, MODIS/Terra flew over SIRTA at 1110 UTC, and the lidar image (Fig. 3a) shows that the cloud is constant during $100 \mathrm{~min}$ around the time of the satellite overpass. The brightness temperature $T_{B}^{\text {cloud }}(8.65 \mu \mathrm{m})$ over SIRTA was $260 \mathrm{~K} \pm 5.6(1 \sigma)$ and was relatively constant for the $20 \times 20 \mathrm{~km}^{2}$ around the SIRTA (Fig. 10), which confirms that the same cloud is measured by both instruments.

The split-window technique is applied using a ground temperature of $281 \mathrm{~K}$ and a true cloud temperature of 

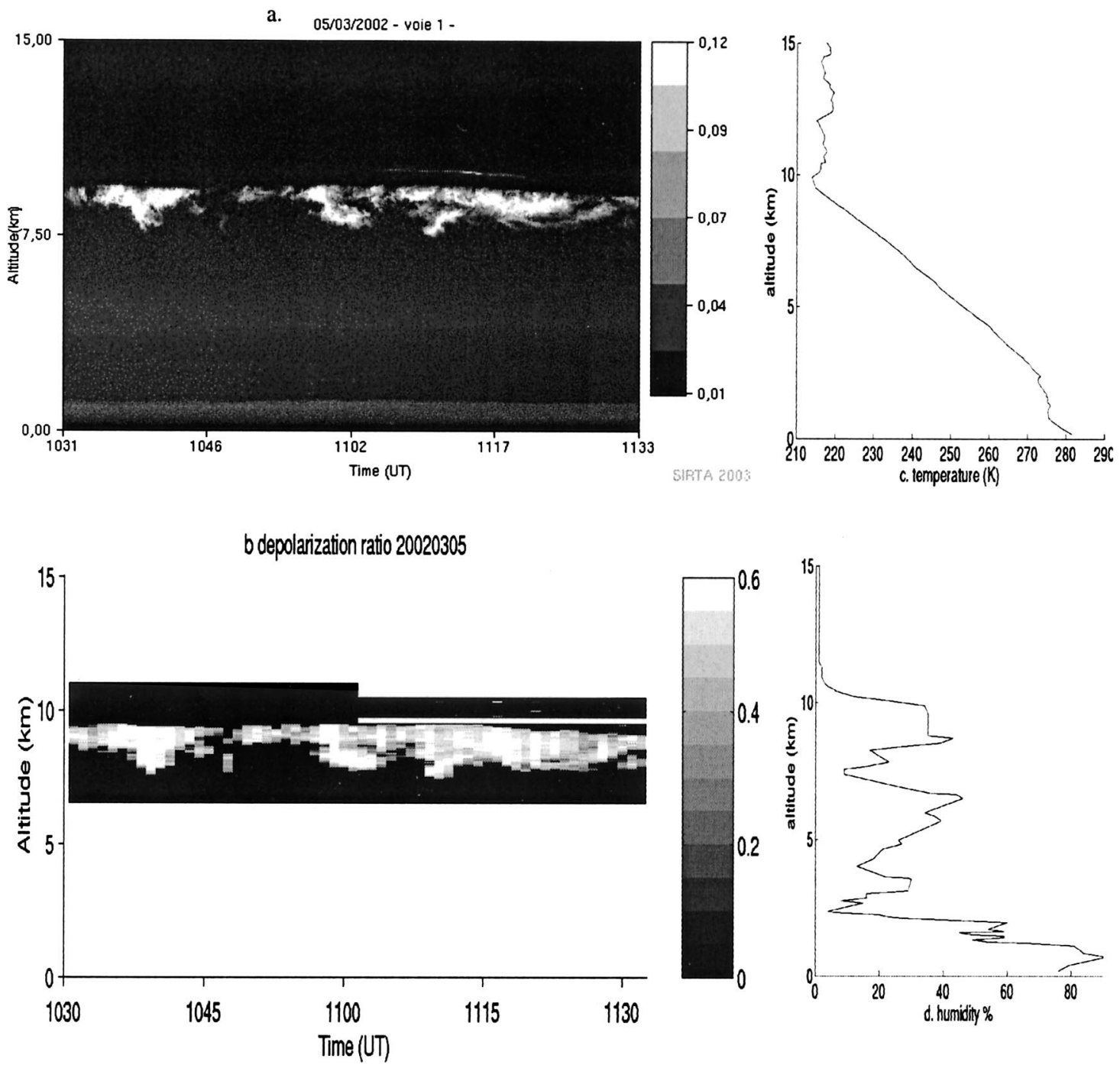

FIG. 9. For 5 Mar 2002: (a) evolution of the 532-nm lidar backscattered signal as a function of time; (b) same as in (a) but for 532-nm lidar depolarized signal; (c) temperature and (d) humidity profile from radiosonde.

$215 \mathrm{~K}$ (estimated temperature at the top of the cloud). The comparisons between observations and simulations have been applied to this case for the three wavelength pairs following the method described in section $3 b(2)$. Figure 11 illustrates the results of the split-window technique using the 11.15- and $12.05-\mu \mathrm{m}$ channels and considering only the particle models that are valid for the three wavelength pairs. This leads to sizes ranging between 19 and $152 \mu \mathrm{m}$ for an aspect ratio between 0.15 and 2. At the time of MODIS overpass (1110 UTC), the depolarization ratio ranged between $40 \%$ and $60 \%$. Comparing those values with the simulations of depolarization ratio as a function of aspect ratio (Fig. 8) leads to aspect ratios $(Q)$ higher than 0.7 . Coupling this aspect ratio constraint with the split-window results allows an elimination of several microphysical models, dashed in Fig. 11. Finally, the particle size ranges between 19 and $54 \mu \mathrm{m}$ for an aspect ratio between 0.7 and 2. Because of the aspect ratio constraint, the size interval has been reduced from $95 \mu \mathrm{m}$ : 19 to $54 \mu \mathrm{m}$ instead of 19 to 152 $\mu \mathrm{m}$.

\section{Results of nine cases studied}

The different stages of the retrieval method have been applied to nine cases of midlatitude cirrus cloud observations. Among those, six cases concern the fall season. The different cases are summarized in Table 4. Their cloud-base temperatures range between $-14^{\circ}$ and $-57^{\circ} \mathrm{C}$, and the cloud-top temperatures range between $-32^{\circ}$ and $-71^{\circ} \mathrm{C}$.

\section{a. Cloud temperature with 532-nm lidar and radiosonde}

Comparing the cloud real temperature (from lidar and radiosonde) with the brightness temperature from MOD- 


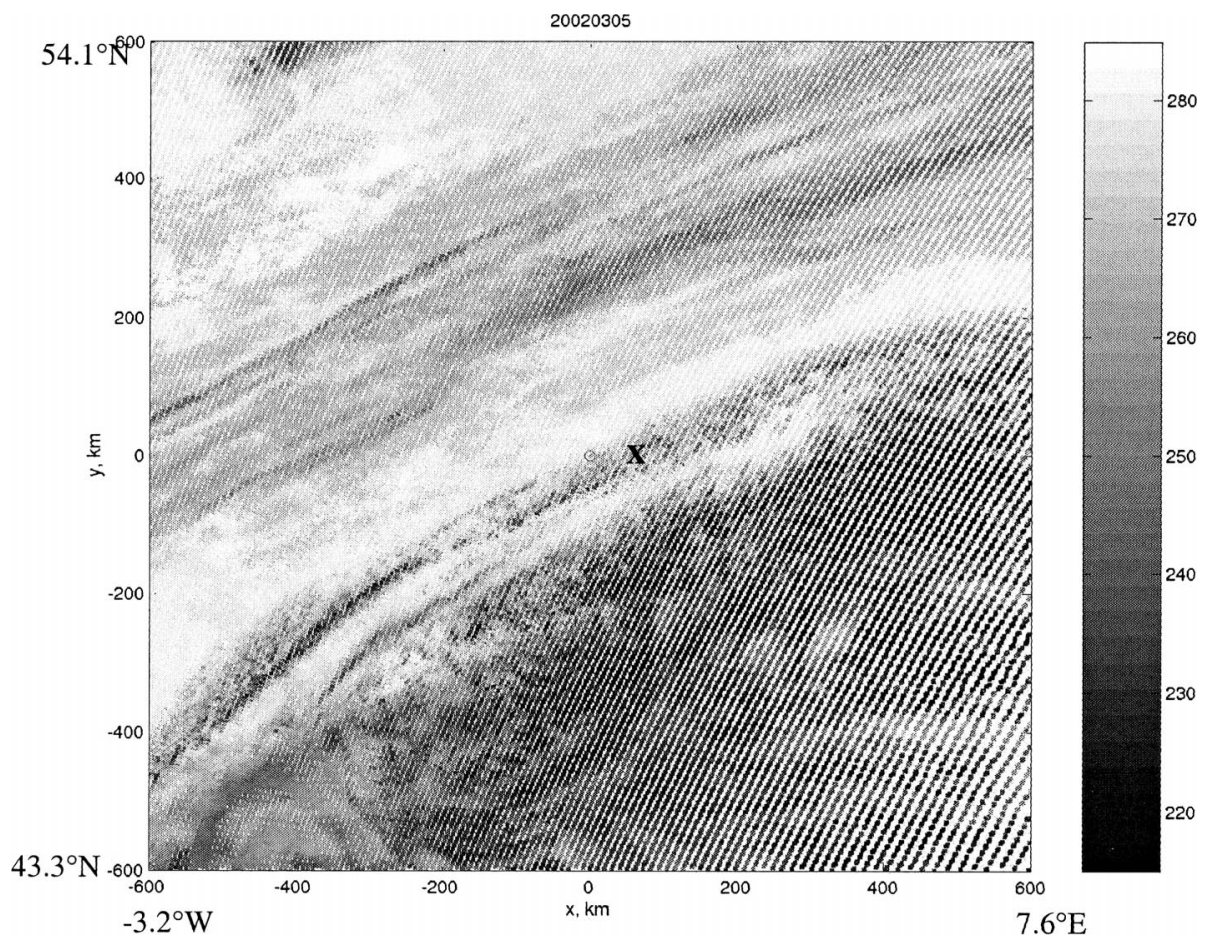

FIG. 10. MODIS image in brightness temperature at $8.65 \mu \mathrm{m}$; " $\mathrm{X}$ " is the location of the SIRTA $\left(48.713^{\circ} \mathrm{N}, 2.204^{\circ} \mathrm{E}\right)$.

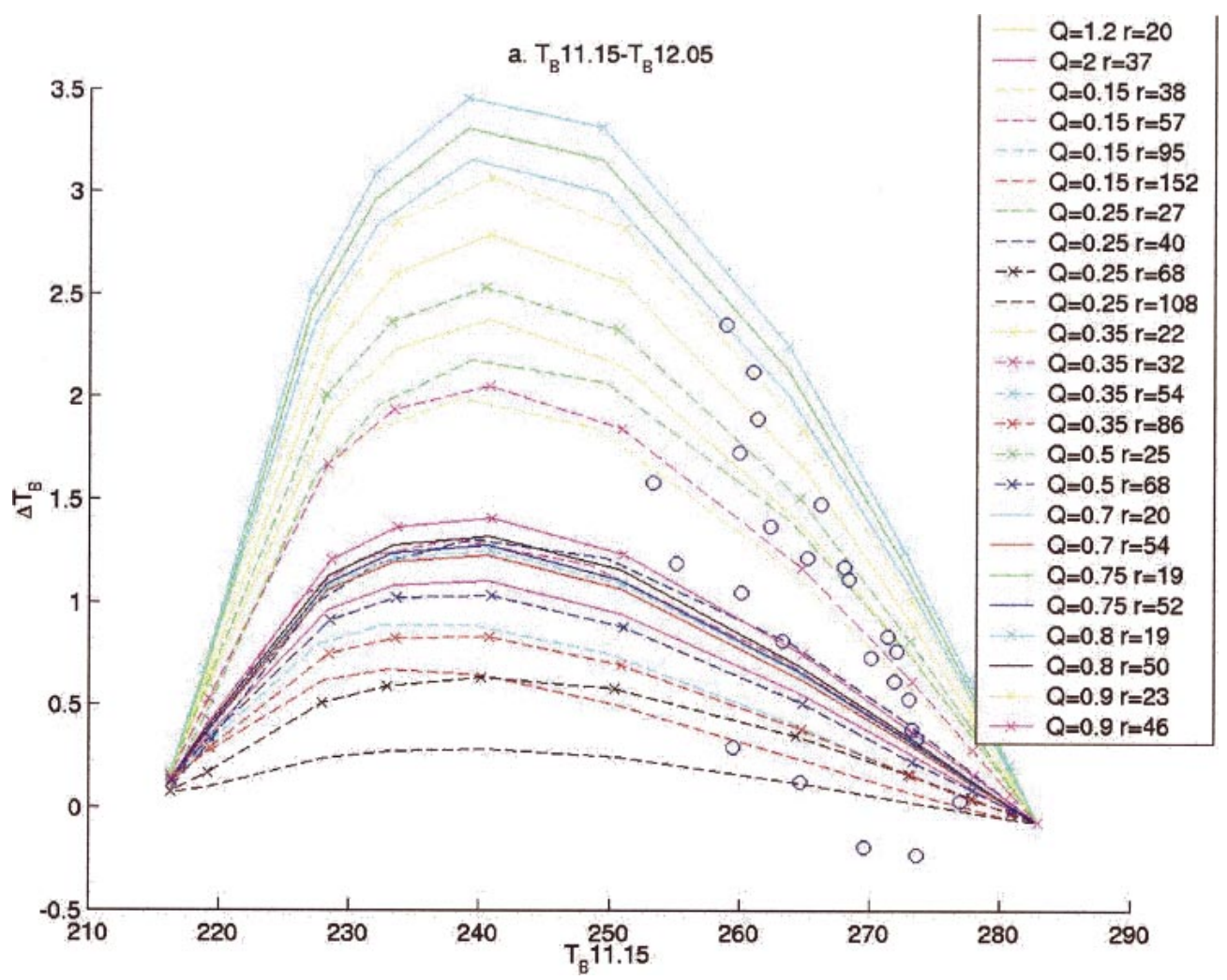

FIG. 11. $T_{B, 11.15 \mu \mathrm{m}}-T_{B, 12.05 \mu \mathrm{m}}=f\left(T_{B, 11.15}\right)$. Curves eliminated by the shape constraint are dashed, and experimental data are in dots. 
TABLE 4. Results of the nine cases studied.

\begin{tabular}{|c|c|c|c|c|c|c|c|}
\hline Date & $T_{\text {base }}(\mathrm{K})$ & $T_{\text {top }}(\mathrm{K})$ & $\begin{array}{l}T_{B, \text { MODIS }} \\
\quad(\mathrm{K})\end{array}$ & Cloud type & $\begin{array}{l}r \text { retrieval with } \\
T_{B 10.15}-T_{B 12.05}\end{array}$ & $\begin{array}{l}3 \text { wavelengths } \\
\text { constraint }\end{array}$ & Shape constraint \\
\hline 5 Mar 2002 & 234 & 214 & 260 & Semitransparent & $\begin{array}{l}18<r<203 \mu \mathrm{m} \\
0.15<Q<9.26\end{array}$ & $19<r<152 \mu \mathrm{m}$ & $\begin{array}{l}19<r<54 \mu \mathrm{m} \\
0.7<Q<2\end{array}$ \\
\hline 2 Apr 2002 & 242 & 225 & 239 & Opaque & $\begin{array}{l}11<r<38 \mu \mathrm{m} \\
0.15<Q<1.41 \\
\text { Sphere water } 12 \mu \mathrm{m}\end{array}$ & $\begin{array}{l}\text { No solution } \\
0.05<Q<\infty\end{array}$ & No solution \\
\hline 1 Oct 2002 & 236 & 219 & $\begin{array}{l}240 \\
280\end{array}$ & Semitransparent & $\begin{array}{l}6<r<38 \mu \mathrm{m} \\
0.15<Q<1.41 \\
\text { Sphere water } 12 \mu \mathrm{m}\end{array}$ & $\begin{array}{l}6<r<19 \mu \mathrm{m} \\
0.15<Q<0.9\end{array}$ & $\begin{array}{l}6<r<13 \mu \mathrm{m} \\
0.7<Q<0.9\end{array}$ \\
\hline 8 Oct 2002 & 251 & 214 & 245 & Opaque & $\begin{array}{l}10<r<38 \mu \mathrm{m} \\
0.15<Q<0.9\end{array}$ & $\begin{array}{l}17<r<19 \mu \mathrm{m} \\
0.15<Q<0.5\end{array}$ & No improvement \\
\hline 14 Oct 2002 & 259 & 241 & 245 & Opaque & $\begin{array}{l}13<r<57 \mu \mathrm{m} \\
0.15<Q<1.41\end{array}$ & $\begin{array}{l}23<r<57 \mu \mathrm{m} \\
0.15<Q<0.9\end{array}$ & $\begin{array}{l}23<r<28 \mu \mathrm{m} \\
0.7<Q<0.9\end{array}$ \\
\hline 6 Nov 2002 & 247 & 217 & 252 & Semitransparent & $\begin{array}{l}17<r<57 \mu \mathrm{m} \\
0.15<Q<0.9\end{array}$ & $\begin{array}{l}17<r<57 \mu \mathrm{m} \\
0.15<Q<0.9\end{array}$ & $\begin{array}{l}20<r<46 \mu \mathrm{m} \\
0.7<Q<0.9\end{array}$ \\
\hline \multirow[t]{2}{*}{19 Dec 2002} & 230 (a) & 202 & 260 & Semitransparent & $\begin{array}{l}8<r<27 \mu \mathrm{m} \\
0.15<Q<1 \\
\text { Sphere water } 12 \mu \mathrm{m} \\
\text { Sphere ice } 12 \mu \mathrm{m}\end{array}$ & $\begin{array}{l}8<r<19 \mu \mathrm{m} \\
0.15<Q<1 \\
\text { Sphere ice } 12 \mu \mathrm{m}\end{array}$ & No improvement \\
\hline & 216 (b) & 202 & 270 & Semitransparent & $\begin{array}{l}0.4<r<203 \mu \mathrm{m} \\
0.15<Q<9.26 \\
\text { Sphere water } 12 \mu \mathrm{m} \\
\text { Sphere ice } 12 \mu \mathrm{m}\end{array}$ & $\begin{array}{l}0.57<r<21 \mu \mathrm{m} \\
0.15<Q<1 \\
\text { Sphere ice/water } 6 \mu \mathrm{m} \\
\text { Sphere ice/water } 12 \mu \mathrm{m}\end{array}$ & $\begin{array}{l}0.57<r<18 \mu \mathrm{m} \\
0.70<Q<1 \\
\text { Sphere ice/water } 6 \mu \mathrm{m}\end{array}$ \\
\hline 19 Feb 2003 & 223 & 211 & $\begin{array}{l}265 \\
270\end{array}$ & Semitransparent & $\begin{array}{l}8<r<152 \mu \mathrm{m} \\
0.15<Q<1 \\
\text { Sphere ice } 12 \mu \mathrm{m} \\
\text { Sphere water } 12 \mu \mathrm{m}\end{array}$ & $\begin{array}{l}8<r<27 \mu \mathrm{m} \\
0.15<Q<1 \\
\text { Sphere ice } 12 \mu \mathrm{m} \\
\text { Sphere water } 12 \mu \mathrm{m}\end{array}$ & $\begin{array}{l}9<r<18 \mu \mathrm{m} \\
0.7<Q<1 \\
\text { Sphere ice } 12 \mu \mathrm{m} \\
\text { Sphere water } 12 \mu \mathrm{m}\end{array}$ \\
\hline
\end{tabular}

IS shows that six cases are semitransparent clouds $\left(T_{B}^{\text {cloud }}>T^{\text {cloud }}\right)$ and three cases are more opaque ( $\left.T_{\text {top }}^{\text {cloud }}<T_{B}^{\text {cloud }}<T_{\text {base }}^{\text {cloud }}\right)$. For the six semitransparent cases, the presence of infrared measurements collocated with lidar information (coupled with temperature profile) allows the application of the split-window technique in positioning the cold foot. For those cases, in the absence of lidar, the infrared brightness temperatures would be wrongly interpreted, leading to false values of particle size.

\section{b. Three-wavelength constraint}

Applying the split-window technique with the MODIS $11.15-\mu \mathrm{m}-12.05-\mu \mathrm{m}$-channel pair leads to a first interval of possible sizes associated with an aspect ratio interval (Table 4). The same thing is done for the three wavelength pairs $(8.65,11.15,12.05 \mu \mathrm{m})$, and only the common results of size retrieval are kept, which constrains the first results. Considering the nine cases, the maximum possible radius retrieved is $152 \mu \mathrm{m}$ for 5 March 2002 and less than $1 \mu \mathrm{m}$ for 19 December 2002. The aspect ratios include both thin plates $(Q \ll 1)$ and columns $(Q>1)$. Moreover, three cases [19 December 2002(a), 19 December 2002(b), and 19 February 2003] contain spherical particles as possible results. At this stage, one case (2 April 2002) cannot be explained by any of the considered microphysical models.

\section{c. Aspect ratio constraint}

The next stage consists of constraining the split-window result of size with aspect ratio information from the 532-nm lidar depolarization [section 3c(2)]. For seven out of eight cases, the aspect ratio constraint allows reduction of the size interval: for 5 March 2002, 14 October 2002, and 6 November 2002, the size interval is reduced by more than $30 \mu \mathrm{m}$; for 19 February 2003, it is reduced by $10 \mu \mathrm{m}$, and for 1 October 2002 and 19 December 2002(b), it is reduced by $3 \mu \mathrm{m}$. Moreover, for 19 December 2002(a and b) and 19 February 2002 the spherical models are eliminated because the depolarization ratio is significantly higher than 0 ( $P$ ranging between $20 \%$ and $60 \%$ ). For one out of eight cases, the aspect ratio constraint does not lead to any improvement (8 October 2002), as the size and aspect ratio intervals 
TABLE 5. Sensitivity of the size retrieved to the position of the cold foot.

\begin{tabular}{|c|c|c|c|c|}
\hline $\begin{array}{l}\text { Position of the } \\
\text { opaque cloud in } \\
\text { simulations }\end{array}$ & $\begin{array}{l}\text { Real temperature } \\
\text { at this position }\end{array}$ & $\begin{array}{l}\text { MODIS brightness } \\
\text { temperature at } 8.65 \mu \mathrm{m}\end{array}$ & $\begin{array}{l}\text { Three-wavelengths } \\
\text { constraint }\end{array}$ & Shape constraint \\
\hline Top of the cloud & $217 \mathrm{~K}$ & $252 \mathrm{~K}$ & $19<r<57 \mu \mathrm{m}$ & $20<r<46 \mu \mathrm{m}$ \\
\hline $\begin{array}{l}\text { Maximum of 532-nm } \\
\text { backscattered signal }\end{array}$ & $237 \mathrm{~K}$ & $252 \mathrm{~K}$ & $\begin{array}{c}10<r<32 \mu \mathrm{m} \\
0.15<Q<0.9\end{array}$ & $\begin{array}{c}11<r<18 \mu \mathrm{m} \\
0.7<Q<0.9\end{array}$ \\
\hline Base of the cloud & $245 \mathrm{~K}$ & $252 \mathrm{~K}$ & $\begin{array}{l}6<r<21 \mu \mathrm{m} \\
0.15<Q<1\end{array}$ & $\begin{array}{c}6<r<13 \mu \mathrm{m} \\
0.7<Q<1\end{array}$ \\
\hline
\end{tabular}

deduced from the three wavelengths were already very small.

\section{Discussion}

The results presented in section 4 show the improvement of the size retrieval due to the lidar/infrared radiometer coupling, but there are still several limitations. The results depend on the a priori choice of the microphysical models. For example, between two different size distributions, the relative difference of size retrieval by a split-window technique is less than $10 \%$ for particles smaller than $55 \mu \mathrm{m}$ and greater than $10 \%$ for larger crystals (Holz 2001). The a priori choices restrict the possible solutions: the ice crystal shapes hypothesis (only hexagonal aspect ratios) and the size distributions are not realistic. Nevertheless, more realistic hypotheses, like aggregate or bullet rosette shapes and monomodal and bimodal size distributions (Baum and Spinhirne 2000; Baum et al. 2000a,b; Chou et al. 2002; McFarquhar et al. 2002) can be considered. But consistent optical properties in the visible (including scattering matrix for polarization), as well as in the far infrared domain, must be available for exactly the same particle sizes and shapes.

Moreover, even if the lidar and radiosonde allow detection of the cloud-base and -top temperature, there is still an uncertainty on the position of the cold foot in the split window. Is it at the top of the cloud, at the altitude of maximum 532-nm backscattered signal, or at the base of the cloud? Table 5 illustrates that for these three different positions of cold foot, the results of size crystal after the three-wavelength constraint and the aspect ratio constraint are different, with (i) a cold foot at the temperature of the cloud top, $20<r<46 \mu \mathrm{m}$, (ii) a cold foot at the temperature of the maximum of 532-nm backscattered signal, $11<r<18 \mu \mathrm{m}$, and (iii) a cold foot at the temperature of the cloud base, $6<r$ $<13 \mu \mathrm{m}$.

This method does not lead to the precise brightness temperature of the cold foot, which corresponds to the most absorbing layer within the cloud. Furthermore, the extension of the current method to satellite observations (CALIPSO) will require addressing several issues. The multiple scattering phenomena are larger for spaceborne lidar than for ground-based lidar. This will lead to less precise determination of cloud boundaries (Spinhirne 1982; Wiegner et al. 1996) as well as difficulties in interpretation of the depolarization ratio. In particular, the identification of spherical particles through the depolarization ratio will be more difficult (Hu et al. 2001). Furthermore, the CALIPSO filters are slightly different and wider than the MODIS filters (Fig. 1), and the CALIPSO brightness temperature uncertainty is $0.3 \mathrm{~K}$, whereas for MODIS it is lower. The uncertainty of the retrieved clear-sky brightness temperature will increase, as the collocation between infrared measurements and radiosonde will not be as good as for a ground-based site, and ground-based emissivities will be less precise. Moreover, the most absorbing layer within a cloud is not necessarily at the top of the cloud, so the cloud boundaries must be known. However, a spaceborne lidar will not see the base of an opaque cloud, restricting the application of the method to semitransparent clouds. For optically thick clouds (particularly frequent in the Tropics), when the lidar beam cannot pass through the cloud, the spaceborne radar would provide the scene identification.

Nevertheless, in comparison with other remote sensing techniques used to retrieve the particle sizes, the current method has some advantages. The classical splitwindow techniques (Inoue 1985; Parol et al. 1991; Giraud et al. 1997) are based on two-wavelength constraints instead of three and so lead to more uncertain results; moreover, it can be applied to few cloud cases because of the difficulty in getting a correct scene identification from passive remote sensing. The active remote sensing techniques (Intrieri et al. 1993, 1995; Matrosov 1999) have the strong advantage of giving information on the vertical variability of the particle size within the cloud, but they tend to overestimate the particle sizes and to miss the semitransparent clouds composed of small particles because of the radar sensitivity.

\section{Conclusions}

The goal of this study was to retrieve the particle size in ice clouds with an improved split-window technique. The split-window technique was improved by (i) scene identification from the 532-nm lidar, (ii) constraint from 
the use of an extra wavelength, and (iii) aspect ratio constraint from 532-nm lidar depolarization. This improved method has been applied to nine cases (section 4). With these improvements, the split-window technique could be applied to most semitransparent clouds and so extend the possible scope of application of the split-window technique to a wider number of cloud cases. The three-wavelength constraint leads to a first range of particle size, and in particular, the $8.65-\mu \mathrm{m}$ channel allows retrieval for particles as large as $76 \mu \mathrm{m}$. The aspect ratio constraint reduces the size interval by more than $20 \%$ for $70 \%$ of the cases, and by more than $65 \%$ for $40 \%$ of the cases.

To evaluate the capability of this new method, future work will consist of comparing the results with in situ observations using intensive field experiment data. Moreover, the current method will be compared to more classical passive remote sensing techniques based on the use of different channels (Minnis et al. 1998; King et al. 2003; Platnick et al. 2003) on a systematic basis during MODIS overpass on the SIRTA. Despite several limitations discussed in section 5, the proposed method could be applied to future CALIPSO lidar and infrared radiometer observations and so lead to a global study of the particle size.

Acknowledgments. The authors are very grateful to the SIRTA ground-based site for providing lidar observations and to NASA Goddard for providing MODIS data. P. Yang's effort is supported by the U.S. National Science Foundation (ATM-0239605).

\section{REFERENCES}

Baran, A. J., P. N. Francis, L. C. Labonnote, and M. DoutriauxBoucher, 2001: A scattering phase function for ice cloud: Tests of applicability using aircraft and satellite multi-angle multiwavelength radiance measurements of cirrus. Quart. J. Roy. Meteor. Soc., 127, 2395-2416.

Baum, B. A., and J. D. Spinhirne, 2000: Remote sensing of cloud properties using MODIS Airborne Simulator imagery during SUCCESS. III. Cloud overlap. J. Geophys. Res., 105, 11 79311804.

— D. P. Kratz, P. Yang, S. C. Ou, Y. Hu, P. F. Soulen, and S. C. Tsay, 2000a: Remote sensing of cloud properties using MODIS Airborne Simulator imagery during SUCCESS. I. Data and models. J. Geophys. Res., 105, $11767-11780$.

— , P. F. Soulen, K. I. Strabala, M. D. King, S. A. Ackerman, W P. Menzel, and P. Yang, 2000b: Remote sensing of cloud properties using MODIS Airborne Simulator imagery during SUCCESS. II. Cloud thermodynamic phase. J. Geophys. Res., 105, 11 781-11 792.

Chepfer, H., G. Brogniez, and Y. Fouquart, 1998: Cirrus clouds microphysical properties deduced from POLDER observations. $J$. Quant. Spectrosc. Radiat. Transfer, 60, 375-390.

_, P. Goloub, J. Riedi, J. F. De Hann, J. W. Hovenier, and P. H. Flamant, 2001: Ice crystal shapes in cirrus clouds derived from POLDER/ADEOS-1. J. Geophys. Res., 106, 7955-7966.

Chou, M. D., K. T. Lee, and P. Yang, 2002: Parameterization of shortwave cloud optical properties for a mixture of ice particle habits for use in atmospheric models. J. Geophys. Res., 107, 4600, doi:10.1029/2002JD002061.
Deirmendjian, D., 1969: Electromagnetic Scattering on Spherical Polydispersions. Elsevier, $290 \mathrm{pp}$.

Dubuisson, P., J. C. Buriez, and Y. Fouquart, 1996: High spectral resolution solar radiative transfer in absorbing and scattering media: Application to the satellite simulation. J. Quant. Spectrosc. Radiat. Transfer, 55, 103-126.

Giraud, V., J. C. Buriez, Y. Fouquart, and F. Parol, 1997: Large-scale analysis of cirrus clouds from AVHRR data: Assesment of both a microphysical index and the cloud-top temperature. J. Appl. Meteor., 36, 664-675.

Heymsfield, A. J., 1975: Cirrus uncinus generating cells and the evolution of cirriform clouds. Part I: Aircraft observations of the growth of the ice phase. J. Atmos. Sci., 32, 799-807.

_ 1993: Microphysical structure of stratiform and cirrus clouds. Aerosol-Cloud-Climate Interactions, P. V. Hobbs, Ed., International Geophysics Series, Vol. 54, Academic Press, 233 pp.

__ , and C. M. R. Platt, 1984: A parameterization of the particle size spectrum of ice clouds in terms of the ambient temperature and the ice water content. J. Atmos. Sci., 41, 846-855.

Holz, R., 2001: Contribution à l'élaboration d'une climatologie globale des cirrus: Etude de l'impact de la variabilité des propriétés optiques infrarouges des cristaux de glace sur la restitution du diamètre effectif à partir d'observations spatiales. Ph.D. thesis, Ecole Polytechinque, $125 \mathrm{pp}$.

Hu, Y., D. Winker, P. Yang, B. Baum, L. Poole, and L. Vann, 2001: Identification of cloud phase from PICASSO-CENA lidar depolarization: A multiple scattering sensitivity study. J. Quant. Spectrosc. Radiat. Transfer, 70, 569-579.

Inoue, T., 1985: On the temperature and effective emissivity determination of semi-transparent cirrus clouds by bispectral measurements in the 10 microns window region. J. Meteor. Soc. Japan, 63, 88-99.

Intrieri, J., G. L. Stephens, W. L. Eberhard, and T. Uttal, 1993: A method for determining cirrus cloud particles sizes using lidar and radar backscatter technique. J. Appl. Meteor., 32, 10741082.

, W. L. Eberhard, T. Uttal, J. A. Shaw, J. B. Snider, Y. Han, B. W. Orr, and S. Y. Matrosov, 1995: Multiwavelength observations of a developing cloud system: The FIRE II 26 November 1991 case study. J. Atmos. Sci., 52, 4079-4093.

King, M. D., and Coauthors, 2003: Cloud and aerosol properties, precipitable water, and profiles of temperature and humidity from MODIS. IEEE Trans. Geosci. Remote Sens., 41, 442-458.

Krupp, C., 1991: Holographic measurements of ice crystals in cirrus clouds during the International Cloud Experiment ICE 1989. Report of the Fourth ICE/EUCREX Workshop, Lille, France, Laboratoire d'Optique Atmosphérique, USTL.

Liou, K. N., 1986: Influence of cirrus clouds on weather and climate processes: A global perspective. Mon. Wea. Rev., 114, 11671199.

Mace, G. G., K. Sassen, S. Kinne, and T. P. Ackerman, 1998: An examination of cirrus cloud characteristics using data from millimeter wave radar and lidar: The 24 April SUCCESS case study. Geophys. Res. Lett., 25, 1133-1136.

Macke, A., J. Mueller, and E. Raschke, 1996: Single scattering properties of atmospheric ice crystals. J. Atmos. Sci., 53, 2813-2825.

Magono, C., and C. W. Lee, 1966: Meteorological classification of natural snow crystal. J. Fac. Sci. Hokkaido Univ. Ser. 7, 2, 320335.

Masuda, K., H. Ishimoto, and T. Takashima, 2002: Retrieval of cirrus optical thickness and ice-shape information using total and polarized reflectance from satellite measurements. J. Quant. Spectrosc. Radiat. Transfer, 75, 39-51.

Matrosov, S. Y., 1999: Retrievals of vertical profiles of ice cloud microphysics from radar and IR measurements using tuned regressions between reflectivity and cloud parameters. J. Geophys. Res., 104, 16 741-16 753.

McClatchey, R. A., R. W. Fenn, J. E. A. Selby, F. E. Volz, and J. S. Garing, 1972: Optical properties of the atmosphere. 3d ed. Publ. 
AFCRL-72-0497, Air Force Cambridge Research Laboratory, Hanscom Air Force Base, 108 pp.

McFarquhar, G. M., and A. J. Heymsfield, 1996: Microphysical characteristics of three anvils sampled during the Central Equatorial Pacific Experiment. J. Atmos. Sci., 53, 2401-2423.

— P. Yang, A. Macke, and A. J. Baran, 2002: A new parameterization of single-scattering solar radiative properties for tropical anvils using observed ice crystal size and shape distributions. J. Atmos. Sci., 59, 2458-2478.

Miloshevich, L. M., and A. J. Heymsfield, 1996: A balloon-borne cloud particle replicator for measuring vertical profiles of cloud microphysics: Instrument design and performance. Proc. 12th Int. Conf. on Clouds and Precipitation, Zurich, Switzerland.

Minnis, P., D. P. Garber, and D. F. Young, 1998: Parameterizations of reflectance and effective emittance for satellite remote sensing of cloud properties. J. Atmos. Sci., 55, 3313-3339.

Noel, V., H. Chepfer, G. Ledanois, and P. H. Flamant, 2001: Computation of single-scattering matrix for non-spherical particles randomly or horizontally oriented in space. Appl. Opt., 40, 43654375 .

$\ldots,-, \ldots$, A. Delaval, and P. H. Flamant, 2002: Classification of particule effective shape ratios in cirrus clouds based on lidar depolarization ratio. Appl. Opt., 41, 4245-4257.

Parol, F., J. C. Buriez, G. Brogniez, and Y. Fouquart, 1991: Information content of AVHRR channels 4 and 5 with respect to the effective radius of cirrus cloud particles. J. Appl. Meteor., 30, 973-984.

Platnick, S., M. D. King, S. A. Ackerman, W. P. Menzel, B. A. Baum, J. C. Riedi, and R. A. Frey, 2003: The MODIS cloud products: Algorithms and examples from Terra. IEEE Trans. Geosci. Remote Sens., 41, 459-473.

Platt, C. M. R., J. D. Spinhirne, and W. D. Hart, 1989: Optical and microphysical properties of a cold cirrus cloud: Evidence for regions of small particles. J. Geophys. Res., 94, 11 151-11 164.

Randall, D., B. Albrecht, S. Cox, D. Johnson, P. Minnis, W. Rossow, and D. Starr, 1996: On FIRE at ten. Advances in Geophysics, Vol. 38, Academic Press, 37-177.

Raschke, E., P. H. Flamant, Y. Fouquart, P. Hignet, H. Hisaka, P. R. Jonas, H. Sundquist, and P. Wendling, 1998: Cloud-radiation studies during the European Cloud Radiation Experiment (EUCREX). Surv. Geophys., 19, 89-138.

Sassen, K., 1991: The polarization lidar technique for cloud research:
A review and current assessment. Bull. Amer. Meteor. Soc., 72, $1848-1866$.

— , and K. N. Liou, 1979: Scattering of polarized laser light by water droplet, mixed-phase, and ice crystal clouds. Part II: Angular depolarizing and multiple-scattering behavior. J. Atmos. Sci., 36, 852-861.

—_ and L. Petrilla, 1986: Lidar depolarization from multiple scattering in marine stratus clouds. Appl. Opt., 25, 1450-1459.

Scott, N. A., 1974: A direct method of computation of the transmission function of an inhomogeneous gaseous medium-I: Description of the method. J. Quant. Spectrosc. Radiat. Transfer, 14, 691-704.

Spinhirne, J. D., 1982: Lidar clear atmosphere multiple scattering dependence on receiver range. Appl. Opt., 21, 2467-2468.

Stamnes, K., S. Tsay, W. Wiscombe, and K. Jayaweera, 1988: Numerically stable algorithm for discrete-ordinate-method radiative transfer in multiple scattering and emitting layered media. Appl. Opt., 27, 2502-2509.

Takano, Y., and K. N. Liou, 1989: Solar radiative transfer in cirrus clouds. Part I: Single-scattering and optical properties of hexagonal ice crystals. J. Atmos. Sci., 46, 3-19.

Toon, O. B., and R. C. Miake-Lye, 1998: Contrails and cloud effects special study (SUCCESS). Geophys. Res. Lett., 25, 1109-1112.

van de Hulst, H. C., 1957: Light Scattering by Small Particles. Dover, $470 \mathrm{pp}$.

Warren, S. G., 1984: Optical constants of ice from the ultraviolet to the microwave. Appl. Opt., 23, 1206-1225.

Wendling, P., R. Wendling, and H. K. Weickmann, 1979: Scattering of solar radiation by hexagonal ice crystals. Appl. Opt., 18, 2663-2671.

Wiegner, M., U. Oppel, H. Krasting, W. Renger, C. Kiemle, and M. Wirth, 1996: Cirrus measurements from a spaceborne lidar: Influence of multiple scattering. Advances in Atmospheric Remote Sensing with Lidar, A. Ansmann et al., Eds., Springler-Verlag, 189-192.

Yang, P., and K. N. Liou, 1998: Single-scattering properties of complex ice crystals in terrestrial atmosphere. Contrib. Atmos. Phys. 71, 223-248

, B. Gao, B. A. Baum, Y. X. Hu, W. J. Wiscombe, S. Tsay, and D. M. Winker, 2001: Radiative properties of cirrus clouds in the infrared $(8-13 \mu \mathrm{m})$ spectral region. J. Quant. Spectros. Radiat. Transfer, 70, 473-504. 